Espacio, Tiempo y Forma, Serie II, Historia Antigua, t. 24, 2011, págs. 47-72

\title{
La presencia de la Sabitum (MÍ.KURUN.NA) en la Jurispridencia de Mesopotamia
}

\author{
The presence of the Sabitum (MÍ.KURUN.NA) \\ in the Jurisprudence of Mesopotamia
}

\author{
Juan Antonio Pino CANo*1
}

\begin{abstract}
RESUMEN
Este artículo trata de la presencia de la sāb itum (Mí.KURUN.NA) en los textos jurídicos de Mesopotamia. Estos dos vocablos fueron los utilizados por los escribas para referirse a la mujer que ejerció el oficio de "cervecera". A excepción de las Leyes Medias Asirias, el "Código" de (Hammurabi), las Leyes de (Ešnunna) y el Edicto de (Ammișaduqa) se redactaron en la primera mitad del segundo milenio a. C. Todas estas fuentes de carácter jurídico afirman que la sābītum dirigía la É.KURUN.NA «casa de la cerveza». En este establecimiento público la sābītum fabricaba $y$ vendía sībum (KURUN.NA) "cerveza» $y$ pequeños artículos. Al mismo tiempo, este corpus de textos legales registra los delitos en los cuales podía incurrir la sābìtum y sus correspondientes castigos en caso de ser transgredidos. La actividad comercial generada por las sabitū

(MÍ.KURUN.NA.MEŠ) alcanzó cierta notoriedad en la sociedad paleobabilónica, al ofrecer préstamos a sus clientes potenciales, mayoritariamente, en metal o en especie. Su

figura sufrió un desprestigio social al ser utilizado su establecimiento como lupanar.
\end{abstract}

\section{ABSTRACT}

This article describes the presence of the sābītum (Mí.KURUN.NA) in the Mesopotamian legal texts. These two words were used by the Scribes in order to refer to the woman that worked as "Alewife». With the exception of the Middle Assyrian Laws, the Code of (Hammurabi), the Laws of (Ešnunna) and the Edict of (Ammișaduqa) were written in the first half of the 2 nd millennium B.C. All this legal sources confirm that the sābītum managed the É.KURUN.NA «Brewpub». In this public establishment the sābitum produced and sold sībum (KURUN.NA) «beer» and basic goods. In addition, this legal texts corpus contains the violation of laws that could be committed by the sābitum as well as the corresponding punishments if she violated them. The Brewing commercial activity generated by the sabitū (MÍ.KURUN.NA.MEŠ) was appreciably notorious in the Paleobabilonic society, as they offered loans to their potential customers, especially by cash or in kind. However, this character lost her prestige in the society since her business premises were used as brothel.

* Doctor en Historia Antigua. Universidad Complutense de Madrid. E-mail: pinocja @ hotmail.com.

1 C/ Puentelarra, no. 18, 2ํㅡ. D, Escal. D. C.P. 28031 Madrid. 


\section{PALABRAS CLAVE:}

sābītum, nadītum, ēntum, ugbabtum, tamkārum, Leyes de Ešnunna, "Código" de Hammurabi, Edicto de Ammișaduqa, Leyes Asirias Medias, Tabernera, Cervecera, Lupanar, "Banquero», Comerciante, Negocio, Préstamo, Depósito, Compraventa, Incumplimiento de Leyes, Delitos y Castigos.
KEYWORDS:

sābītum, nadītum, ēntum, ugbabtum, tamkārum, Laws of Eshnunna, "Code" of Hammurabi, Edict of Ammisaduqa, Middle Assyrian Laws, Tavern Owner, Alewife, Brothel, «Banker», Trader, Business, Loan, Deposit, Purchase Agreement, Violation of Law, Offenses and Punishments.

\section{INTRODUCCIÓN HISTÓRICA}

La derrota y posterior extinción del imperio de Ur III en el año 2002, debido a una invasión de tribus amorritas y del Elam, trajo consigo una nueva fragmentación política en Mesopotamia. A principios del segundo milenio se generan en Babilonia una serie de ciudades-Estado independientes. Con Ǐbi-Erra (2019-1987), gobernador de la ciudad de Isin, da inicio la denominada Dinastía primera de Isin, vigente desde el 2019 hasta 1937. Poco después, otro gobernador amorrita, Šin-kašid (1865-1833), fundó otra dinastía en Uruk. Entre sus hechos más destacados figuraba la construcción de un templo en la ciudad de Durum, nombrando a su hija Nin-šatapad suma sacerdotisa. Simultáneamente, diferentes gobernadores amorritas fundaron otras tantas dinastías locales en las ciudades de Ešnunna, Sippar, Kiš, Larsa, Der, Aššu y Mari, entre otras.

Las dinastías amorritas se encontraban estrechamente comunicadas con otras tribus localizadas al norte y al oeste de Mesopotamia. La complejidad y amplitud de dichas relaciones se debe a la información sorprendente que contienen los archivos diplomáticos encontrados en el palacio de Mari. El reino amorrita de Larsa había anexionado a su rival, Isin, y dominaba la mitad meridional de Mesopotamia. Babilonia consiguió ser el Estado más fuerte y poderoso en la región de Acad. Su rey más destacado, Hammurabi, realizó una política basada en un compendio de estrategia militar, diplomática y administrativa, logrando unificar de nuevo Mesopotamia. Al norte de Babilonia se encontraban los poderosos reinos de Mari y Ešnunna que fueron anexionados en su momento por Hammurabi.

En cuanto a las instituciones estatales, representadas por el Palacio y el Templo, tuvieron que ceder parte de su monopolio, en cuanto, a la propiedad de la tierra y el control del comercio para cederlo a los tamkarū. Este cambio originó grandes transformaciones económicas y sociales. Para plasmar esta nueva realidad ya no eran válidos los «textos de reformas" sumerios (Enmetena, UruKAgina y Gudea), ni los «códigos» legales de (Šulgi, Lipit-lštar)².

Los nuevos dirigentes de las tribus amorritas mandaron a sus respectivos escribas la redacción de una nueva reglamentación social y económica que se ajus-

2 Para una visión de las normas jurídicas para regular la vida de las primeras ciudades-Estado de Súmer, vid. F. L. Peinado-F. Lara González (2001) passim. 
tase a los nuevos tiempos. De esta manera, surgieron nuevas normas legales recogidas en las Leyes de (Ešnunna), el «Código» de Hammurabi, las llamadas ( Leyes del Rey»), las («Leyes sobre moratoria y exención de tasas»), el Edicto de Ammișaduqa, los («Contratos y procesos babilónicos») y, posteriormente, las Leyes Asirias Medias ${ }^{3}$. Las fuentes de carácter legal aquí recogidas en las que aparece representada la sābītum se presentan en orden cronológico.

\section{LA SABITUM EN LOS TEXTOS MITOLÓGICO-HISTÓRICO- LITERARIOS}

La Lista real sumeria 4 es la primera fuente que registra el nombre de Ku-Babba, a la que califica de «tabernera». Curiosamente, fue considerada el único soberano de la breve Dinastía III de Kiš, contradiciendo el hecho de que, el poder real era hereditario y se transmitía de padres a hijos. Posteriormente, fue identificada con la diosa Ku-baba, deidad venerada principalmente en el norte de Mesopotamia. Esta fusión de los nombres enlazaría con un aspecto característico de este período histórico, que consistía en aglutinar en manos del dirigente político el poder divino y secular.

El segundo testimonio de una mujer tabernera en las fuentes lo tenemos en la

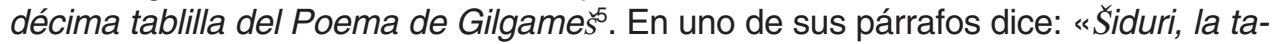
bernera, que habitaba en la orilla del mar, residía allí sobre un trono (...); le habían hecho una cuba, le habían hecho una prensa de oro, iba cubierta con un velo (...)». Se ha propuesto que su nombre es una derivación del hurrita, šiduri, con el significado de « muchacha». Este término es empleado también como sobrenombre de la diosa juvenil Hebat.

El nombre de Šiduri aparece igualmente con el significado de «Ella es mi refugio», una denominación que se corresponde con la imagen preconcebida que de ella tenían los viajeros del antiguo Oriente. Su nombre parece ser de origen extranjero aunque se le haya querido prestar una etimología babilónica. La tradición semita reinterpretó este antropónimo a la acadia ( $S \bar{S} \bar{l}-d \bar{r} r \bar{I})$ «Ella es mi muralla» y la calificó como una «diosa de la sabiduría» ('/štar ne-me-qí) ${ }^{6}$. El asiriólogo italiano D’Agostino interpreta que la diosa Šiduri era una personificación de la diosa acadia, Ištar, como deidad solícita del bien del hombre ${ }^{7}$. En el Poema de Gilgameš, Šiduri aparece designada como tabernera divina, pues así lo recoge el texto al incluir el signo cuneiforme que alude al predeterminativo (dingir), unido al término kussû, en sumerio, GIŠ.GU.ZA que hace referencia al «trono (de dioses y de reyes)»8.

3 Abreviado (LAM).

4 Documento de carácter mitológico-histórico, redactado en lengua sumeria. Dicha fuente se encuentra contenida en el Prisma WB, 1923.444 donde expone la Historia de los soberanos sumerios.

5 Versión asiria, Col. I. II. 1-50. vid. F. L. Peinado (1997) pp. 145-146.

6 Vid. J. Sanmartín (2005) pp. 247 y 263.

7 Vid. F. D'Agostino (2007) p. 158

8 Vid. CAD (1971) pp. 587-593.; F. L. Peinado (1997) p. 298. 
Si extrapolamos la información que recoge la tablilla $X$ del Poema de Gilgameš, se puede decir que, para los habitantes del antiguo Oriente, la sābītum era una mujer que vendía cerveza -la bebida más popular en Mesopotamia- elaborada por ella misma. Cuando el texto alude a que su morada se encontraba próxima al mar, sorprende el hecho de que, una tabernera tuviese su establecimiento alejado de los lugares concurridos para despachar y consumir esta bebida. La idea de alejamiento de las tabernas de las zonas habitadas da a entender que, se encontrarían ubicadas en la periferia de las ciudades, o bien, en el cruce de caminos, próximas a las principales rutas terrestres por donde transitaban las caravanas.

Las sabitū pudieron ser útiles como informantes a los viajeros en cuanto a rutas y caminos que debían elegir. La alusión en el texto del Poema de Gilgameš al "cántaro», "cuba», «tinaja»y, a la prensa de oro, no hace más que señalar los utensilios de trabajo empleados por la tabernera para fermentar y conservar la cerveza. En cuanto al velo que llevaba puesto Šiduri es un claro símbolo y distintivo de mujer casada. Su utilización se convertía en una señal de distinción y su empleo en un privilegio.

La sābìtum tuvo en otras lenguas diferentes significados. En lengua hitita se la conocía por Ziduri ${ }^{9}$. La palabra sābītum parece provenir del topónimo Sabu ${ }^{10}$, un monte famoso por sus viñas y lo habría tomado por semejanza fonética a partir del vocablo sābum con las acepciones de «tabernero», «cervecero».

\section{LA SABITUM EN LA LEGISLACIÓN PALEOBABILÓNICA: PROCEDENCIA DE LOS TEXTOS}

Las principales colecciones jurídicas que hasta la fecha recogen en su corpus de leyes la presencia de la tabernera (MÍ.KURUN.NA) y a su establecimiento público, son por orden cronológico: las Leyes de Ešnunna" ${ }^{11}$, el "Código» de Hammurabi $^{12}$, el Edicto de Ammișaduqa ${ }^{13}$ y, finalmente, las Leyes Asirias Medias ${ }^{14}$.

9 La palabra acadia sābītum significaba en lengua hurrita «moza» 0 «jovencita». vid. F. L. Peinado (1997) n. (2) en p. 297.; E. Laroche (1966), no 1.562.

${ }_{10}$ La divinidad sumeria del vino se llamaba Geštinanna. Literalmente, su nombre significaba «viña celeste». Ocupaba un puesto secundario en el Panteón sumerio. Fue diosa consorte de Ningišzida y aparece en el mito del Descenso de Inanna a los Infiernos, intentando rescatar a su hermano Dumuzi de los dominios de Ereškigal después de que fue abandonado por Inanna. vid. F. L. Peinado (1988) n. (15) en p. 299.

11 Abreviado (LE).

$12(\mathrm{CH})$.

${ }_{13}$ (EAS).

14 (LAM). 


\subsection{Leyes de Ešnunna: Descubrimiento, datación cronológica y descripción externa}

En la colección jurídica de Ešnunna ${ }^{15}$ se encuentran recogidas las leyes más antiguas redactadas en lengua acadia. En cuanto a su datación cronológica no ha podido ser fijada de modo preciso la fecha de redacción y posterior promulgación. En un principio se consideró obra de Bilalama (que reinó en torno al 1800) al leer su nombre de forma errónea ${ }^{16}$. Posteriores estudios han determinado rebajar la fecha de redacción en el intervalo de tiempo que abarca los reinados de Ipiq Adad II (1862-1818) y el de su hijo Daduša (1816-1779). La primera edición de esta colección jurídica ${ }^{17}$ fue llevada a cabo por el asiriólogo americano A. Goetze ${ }^{18}$ en el año 1948.

Las Leyes de Ešnunna han aparecido redactadas en tres tablillas de arcilla pero ninguna de ellas se encuentra completa. Han sido denominadas convencionalmente con las letras $A^{19}, B^{20}$ y $C$. Los manuscritos $A$ y $B$ de contenido idéntico, si exceptuamos algunas variaciones de tipo ortográfico, gramaticales y jurídicas. Tales tablillas fueron descubiertas en el tell de Abu Harmal' ${ }^{21}$. El manuscrito C, fue descubierto en el transcurso de unas excavaciones realizadas sin autorización a comienzos de la década de los años ochenta, en el enclave de Tell Haddad.

Las tablillas $\mathrm{A}$ y $\mathrm{B}$ tiene cada una dos columnas, mientras que la tablilla $\mathrm{C}$ solo una. El manuscrito A es el que se encuentra en mejor estado de conservación. Del $\mathrm{B}$ tan solo se conserva la mitad inferior de la tablilla, mientras que del $\mathrm{C}$ únicamente la mitad.

La estructura del corpus de Leyes consta de un breve prólogo. Un cuerpo legal con 60 artículos, todos ellos a excepción del último se encuentran en perfecto estado de conservación. Contienen una variedad temática en cuanto a los asuntos

15 Importante ciudad mesopotámica descubierta por el arqueólogo holandés $\mathrm{H}$. Frankfort en las campañas arqueológicas llevadas a cabo entre los años 1930 y 1936 . Se encontraba oculta en la colina de Tell Asmar. Fue considerada la capital de un reino, el país de Warum, ubicado en la llanura del Diyāla, al este de Mesopotamia, entre el río Tigris y los montes Zagros. Con el tiempo se convirtió en un importante centro político y económico. Su independencia como Estado concluyó cuando fue conquistada por Hammurabi e incorporada a su imperio.

${ }_{16}$ E. Szlechter (1978) pp. 109-219, propone que la autoría de estas Leyes bien pudo ser Ipiq-Adad II (1862-1818) e incluso su hijo Daduša (1816-1779).

17 Hay autores que prefieren hablar de Leyes en vez de «Código», debido a que, la colección jurídica no puede ser considerada como un código. Los preceptos hasta la fecha conocidos forman parte de un trabajo de mayor envergadura que, en opinión de los especialistas sirvió de manual para funcionarios jurídicos y de la corte.

18 A. Goetze (1950) pp. 161-163

19 Tablilla con el número de catalogación IM 51059. Bagdad: Iraq Museum: IM 51059. Ediciones; Goetze; 1948a: Goetze; 1948b: Goetze; 1956.

20 Tablilla con el número de catálogo IM 52614. Es más tardía que la tablilla A. Los dos manuscritos se encuentran en el Museo Iraquí de Bagdad.

21 Nombre moderno de la antigua ciudad de Šaduppûm, próxima a Bagdad, entre 1945 y 1947 por el arqueólogo iraquí, Taha Baqir. Tal localidad se encontraba en la zona de influencia política de Ešnunna. 
que tratan. Así, el listado de precios y tarifas de forma detallada por parte del legislador a comienzos de la colección tendría como finalidad la de estabilizar la economía. La ausencia del epílogo no quiere decir que no lo incorporase sino que no ha sido descubierto. Se puede aventurar que pudiese encontrarse en el resto del contenido que falta en las tablillas A, B y C.

Una de las características principales de las Leyes de Ešnunna es que se aplica en pocos supuestos la Ley del Talión. De su articulado, tan sólo los números 15 y 41 hacen referencia a la sābītum. El décimo-quinto, pertenece a la sección de las limitaciones a la actividad económica y el cuadragésimo-primero, se ajusta a la temática referente a la custodia, depósitos y venta.

\subsubsection{Transliteración y Traducción ${ }^{22}$}

Artículo 15: B. Col. I, II. 10-11

10) i-na qa-ti wardim (SAG.ìR) ù amtim (GÉME) tamkārum (DAM.GÀR) ù sa-bitum $^{23}$ 11) kaspam ${ }^{24}$ še-a-am ${ }^{25}$ šipatam (SíG ${ }^{26}$ ellam (İ.GIŠs) ${ }^{27}$ a-di ma-di / ti-im ${ }^{28}$ ú-ul i-ma-ha-ar ${ }^{29}$.

22 Vid. R. Yaron (1988) pp. 51-53 y 68-69 (texto en escritura paleobabilónica, transliteración, traducción y notas).; F. Lara Peinado-F. Lara González (1994) pp. 116 y 130 (estudio preliminar, traducción y notas).; J. Sanmartín (2005) pp. 65 y 70 (introducción, traducción y notas).

${ }^{23}$ El carácter bilingüe de los escribas mesopotámicos queda de manifiesto al utilizar unas veces el acadiograma (sa-bi-tum) como ocurre en los artículos 15 y 41 de las (LE) o del sumerograma, como ocurre en el $(\mathrm{CH})$ y el (EAS) al utilizar el sumerograma correspondiente, Mí.KURUN.NA, para referirse indistintamente a la «tabernera» y «cervecera».

${ }_{24}$ Término acadio, en sumerio, KÙ.BABBAR, «plata». Metal que al desempeñar la función de patrón tipo tuvo una gran importancia en la vida económica en Mesopotamia. Este metal se empleó para realizar pagos y se pesaba previamente antes de realizar la transacción. Durante el período PaleobabiIonio, el valor de la plata en relación con el oro era bastante sólido: un šiqlum de oro equivalía a seis šiqlum de plata. Durante el reinado de Hammurabi, el šiqlum, en sumerio, GíN, era considerada una medida de peso que equivalía a 180 gramos, alrededor de 8, 33 gramos en nuestro sistema métrico decimal. El escriba omite el pesado en plata que el esclavo y la esclava querían entregar a la sābītum y al tamkārum, así como en concepto de qué.

25 Acusativo de ̌̌e'um, en sumerio, ŠE «cebada», «cereal», «grano». El sistema «monetario» en el área mesopotámica era ambivalente. Por un lado, la cebada que se medía en litros, y, por otro, la plata. Una de las primeras medidas que realiza la ciudad-estado de Exnunna es la de establecer la equivalencia entre los dos valores «monetarios». La relación se estableció para que 250 litros de cebada equivaliesen a 8,30 gramos de plata.

${ }^{26}$ Acusativo de šipātum, palabra acadia, en sumerio, SIKI, SíK, SíG «lana». A lo largo de la historia mesopotámica, el trabajo de la lana recaía principalmente en las esclavas, que, en los talleres de los templos y palacios, se encargaban de la realización de los distintos procesos (carmenado, peinado, lavado, desengrasado e hilado). Las Leyes de Ěnunna en su artículo primero establece la equivalencia entre la lana y la plata. Se cambiaba seis MA.NA/manû «minas» de lana por un GíN/šiqlum de plata. Traducido a nuestro sistema métrico decimal vendría a ser 3 kilográmos de lana por 180 gramos de este metal.

${ }^{27}$ El escriba utiliza el sumerograma, İ.GIŠ, «aceite vegetal». Se refiere al aceite de sésamo. Añade el adjetivo, ellum, en sumerio, KÙ; ŠEN; SIKIL, con las acepciones de «puro», «limpio», «brillante». Este producto oléicola junto al grano y la lana formaron parte de las raciones de los esclavos. La demanda de aceite era sin embargo muy grande, ya que no solo se empleaba en la alimentación y fabricación de ungüentos sino que era utilizado también para la iluminación y los diferentes usos rituales del templo. 


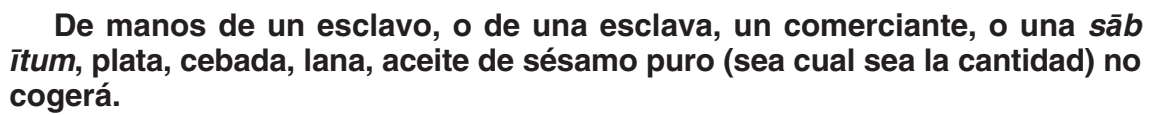

Artículo 41: A. Col. III, II. 30-31; B. Col. III, II. 14-16

30) šum-ma ubarum (U.BAR) ${ }^{30}$ na-ap-țà-rum ${ }^{31}$ ù mu-du-ú32 šikar-šu (KAŠ-šu) i-

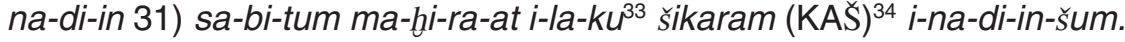

Si un ubārum, un napțarum o un mūdûm su cerveza entrega, la tabernera al precio que haya la cerveza le dará.

\section{2. «Código» de Hammurabi: Descubrimiento, datación cronológica y descripción externa}

En el año 1792, Hammurabi, sexto rey de la dinastía primera de Babilonia asciende al trono. En su cuadragésimo año de reinado, promulgó un conjunto de leyes, las mandó grabar en una serie de estelas de piedra y las hizo colocar en diferentes lugares de su imperio. Una de ellas, trabajada en diorita negra fue descubierta por J. de Morgan entre 1901 y 1902, en la localidad de Susa (Irán). Históricamente, esta estela fue trasladada como botín de guerra por el rey elamita, Shutruk-Nakhunte alrededor del año 1200. Actualmente, se encuentra en el Museo

${ }^{28}$ adi mādim. Esta expresión, cuya lectura y significado son inciertos. La traducción aproximativa sería «junto con muchas cosas». Otras traducciones que se proponen: «sea cual sea la cantidad», «en grandes cantidades» que proviene de mādim< mādum «mucho», «numeroso», «abundante» $(m a) a ̄ d u)$.

293 sg. del Presente G de mahārum (a/u) «recibir», «coger».

30 Este término ha sido traducido de diversas maneras. Así, F. Lara Peinado (1994) p. 130 «ambulante». R. Jiménez Zamudio (2002) p. 266 «extranjero», «desconocido». J. Sanmartín (1999) n. (104) en p. 77 dice que el ubarum era un «extranjero», un «meteco», y, como tal, un «protegido»; una persona foránea que gozaba del privilegio de residir libremente dentro de la comunidad. S. Lafont (1999) p. 420 traduce «residente».

${ }^{31}$ La etimología del término napța/iru vendría relacionada con el verbo patāru $(m)(a / u)\left(D_{8}\right)$ «soltar», «liberar», «rescatar»; «retirar», en el sentido de desligarse, marcharse, trasladarse de un lugar a otro. Para J. Sanmartín, el término acadio, naptarum aludía a una persona extranjera que residía en alguna casa específica utilizada para albergar a la gente foránea, o bien, de un cautivo en espera de rescate. S. Lafont traduce «residente».

32 mūdû Participio del verbo idû, edû (-»; -e) «conocedor», «experimentado en». El sentido del texto es ambiguo. Lo más probable es que se tratasen de personas que se movían en ambientes comerciales, pero no sabemos si eran vendedores autónomos o pertenecieron a alguna institución civil o religiosa. En cualquier caso, este artículo trata de la reventa de bebidas alcohólicas. Lo que no queda claro es si la tabernera compraba la cerveza a esos hombres y revendía en el mercado, o por el contrario, es la tabernera la encargada de comercializarla por ellos por tener el acceso restringido a dicho espacio económico. El precio oficial lo establecía el Estado y la expresión «al precio que haya» presupone un precio fijo para esta bebida alcohólica y que no es recogida. Al mismo tiempo, desconocemos la cantidad de cerveza entregada por el ubārum, el napțarum y el mūdû a la tabernera.

${ }^{33}$ Literalmente, «al precio que haya»; es decir, al precio que este estipulado la cerveza en el mercado.

34 En cuanto a las bebidas alcohólicas, vid. W. Röllig (1970) passim.; J. J. Glassner (1991) pp. 127146.; M. Molina (2001) pp. 15-38. 
del Louvre. Con respecto a sus medidas, tiene una altura de 2, 25 metros y asemeja una forma cilíndrica.

La inscripción que contiene dicha estela se encuentra redactada en lengua acadia. Su texto fue traducido y publicado por el sacerdote francés, Jean-Vincent Scheil. Consta de prólogo, cuerpo jurídico y epílogo. Una de las cosas que más llama la atención es la diferenciación estilística entre el cuerpo de leyes por un lado, y, el prólogo y epílogo por otro. Si en el articulado, el escriba babilonio emplea una escritura técnica y asequible en cuanto a la sencillez, no pude decirse lo mismo en cuanto al prólogo y epílogo, puesto que, utiliza un lenguaje más literario y, al mismo tiempo, más arcaizante.

Hammurabi no realizó un «código» de leyes innovador, sino que se sirvió de la legislación anterior, eso sí, modificándola en aquellos apartados que le convenían para ajustarse a las necesidades que su imperio necesitaba. A diferencia de las $L e-$ yes de Ešnunna, Hammurabi si hizo asentar en la Ley del Talión su Derecho penal para aquellas personas que se encuadraban dentro de la misma categoría social. En definitiva, su obra legislativa fue regresiva con respecto a «códigos» precedentes.

Este corpus de leyes que constituye el «Código» de Hammurabi deja entrever una sociedad muy jerarquizada, clasista con un Estado fuertemente centralizado, además de ser una obra jurídica bastante significativa. Desde el punto de vista literario, este texto jurídico alcanzó un alto valor y sirvió de modelo para futuras obras de carácter legislativo. Fue un texto reiteradamente copiado en las escuelas de escribas.

Los 282 artículos que consta el "Código» de Hammurabi, se estructuran en diversos apartados. El que hace referencia a la tabernera se encuadra dentro del de asuntos relacionados con los bienes patrimoniales. Tal sección trataba de las tabernas y sus propietarias, las sabitū $(108,109$ y 111) y las naditū (110).

\subsubsection{Transliteración y Traducción ${ }^{35}$}

Artículo 108: Col. XXV, II. 15-25

15) šum-ma sābītum (Mí.KURUN.NA) 16) a-na šịm] (Š́[M]) šikarim (KAŠ) 17) še`am (ŠE) la im-ta-har 18) i-na abnim $\left(\mathrm{NA}_{4}\right)$ ra-bi-tim6 19) kaspam (KÙ.BABBAR) im-ta-ḩar 20) ù mahīr (GANBA, KI.LAM) šikarim (KAŠ) 21) a-na mahīr (GANBA,

35 Vid. E. Bergmann (1953) (texto en escritura paleobabilonia).; G. Driver-J. Miles (1955) II (transliteración, traducción, notas filológicas y glosario).; R. Borger (1979) I, pp. 23-24 (texto transliterado); II, pp. 295-296 (texto en escritura neo-asiría los artículos).; Marta T. Roth (1995) (texto normalizado, traducción inglesa, introducción y breve comentario).; A. Finet (2002) p. 79-80 (traducción y notas) pp.119-120 (traducción y notas).; R. Jiménez Zamudio (2002) p. 29 (texto transliterado y notas filológicas).; J. Sanmartín (1999) pp. 119-120 (textos transliterados y anotados, signario, glosario y copias cuneiformes).; F. L. Peinado (2008) (estudio preliminar, traducción y notas).

${ }^{36}$ abnim ( $\mathrm{NA}_{4}$ ) ra-bi-tim con los significados de «pesa grande» y «gran piedra». Los mesopotámicos dispusieron de numerosas unidades de peso. Tal término designaba el peso empleado para evaluar los bienes dados por el cliente en contrapartida de su compra. vid. S. Lafont (1999) n. (34) en p. 419. J. San- 
KI.LAM) še’im (ŠE) um-ta-ți 22) sābītam (Mí.KURUN.NA) šu-a-ti 23) ú-ka-an-nu-šima 24) a-na me-e 25) i-na-ad-du-ú-ši.

Si una sābìtum como precio de la cerveza cebada no ha recibido en un peso grande ( $y$ ) plata ha recibido, pero la cantidad de cerveza con respecto a la cantidad de cebada ha empequeñecido (entonces) a esa sābītum (se) lo probaran (y) a las aguas (ellos) la arrojarán.

Artículo 109: Col. XXV, II. 26-35

26) šum-ma sābītum (MÍ.KURUN.NA) 27) šà-ar-ru-tum 28) i-na bītī (É)-ša 29) ittar-ka-šú-ma 30) sà-ar-ru-tim šu-nu-ti 31) la iṣ-șa-ab-tam-ma 32) a-na ekallim (É.GAL) 33) la ir-te-de-a-am 34) sābītum (MÍ.KURUN.NA) ši-i 35) id-da-ak.

Si una sābìtum unos conspiradores en su casa se han reunido y (a) esos conspiradores no ha capturado y, al Palacio (ella) no los ha conducido, esa sābìtum será golpeada.

Artículo 110: Col. XXV, II. 36-44

36) šum-ma nadītum (LUKUR) ēntum (NIN.DINGIR) 37) ša i-na gagîm (GÁ.GI. A) 38) la wa-aš-ba-at 39) É.KURUN.NA ip-te-te 40) ù lu a-na ši-ka-rim (KAŠ) ${ }^{37}$ 41) a-na É.KURUN.NA 42) i-te-ru-ub 43) a-wi-il-tam šu-a-ti 44) i-qal-lu-ú-ti.

Si una nadītum (o) una ēntum que, en el gagûm no reside, una taberna ha abierto, o bien por cerveza a la taberna ha entrado (a) esa mujer (que) la quemen.

Artículo 111: Col. XXV, II. 45-49

45) šum-ma sābītum (MÍ.KURUN.NA) 46) 1 pīham (PIHUU, KAŠ.Ú.SA.KA.GAG) ${ }^{38}$ 47) a-na qí-ip-tim id-di-in 48) i-na ebūrim $\left(\mathrm{BURU}_{14}\right)$ 49) 5 šâ še’am (Š ${ }^{39}$ i-le-qé.

martín (1999) n. (160) en p. 165, recoge que la pesa hacía referencia al curso más alto del mercado. vid. también $\mathrm{CH}$ Art.73+e.

37 Para cuestiones relativas a la apertura de una taberna como negocio o que estas dos categorías de sacerdotisas entran en una taberna para comprar cerveza y después venderla con un interés mayor. vid. M.T. Roth (1999) pp. 445-464.

${ }^{38}$ Estos logogramas hacen referencia a un recipiente con tal nombre donde contenía una variedad específica de cerveza y cuya cantidad exacta desconocemos. En los textos encontrados en Mari se hace alusión a un pīhum que contenía 20 qû o SìLA en sumerio. En la tabla metrológica babilónica, 1 qû equivalía a 1 litro. La entrega por parte de la tabernera de una cántara- pīham a crédito (a-na qí-ip-tim) será compensada en contrapartida por el beneficiario/a con la cantidad de 50 qû de cebada. Este crédito pagado en cereal y no en plata, estaría apoyado por parte del Palacio. Con ello quiso favorecer el uso de los cereales, especialmente, en el tiempo de la recogida de la cosecha. Sin embargo, como apunta el decreto décimo-séptimo del Edicto de Ammișaduqa, si la tabernera en vez de prestar, fiaba su mercancía, tanto en cerveza como en cebada no podía apremiar al beneficiario/a una vez se iniciase el tiempo de recogida de la cosecha.

395 šâ=BANIA, lectura que ofrecen R. Borger (1979) I, p. 24 y R. Jiménez Zamudio (2002) p. 29. En cambio F.Lara Peinado (2008) p. 20 «recibirá cincuenta QA de grano» y J. Sanmartín (1999) p. 120 «50 silas de cebada». 
Si una sābītum, una cántara-pībum (de cerveza) a crédito entregó, en tiempo de cosecha, 50 qû de cebada recibirá.

\subsection{Edicto de Ammișaduqa: Descubrimiento, datación cronológica y descripción externa}

Aquellos supuestos de carácter jurídico-socioeconómico que no habían quedado regulados en el «Código» de Hammurabi, se resolvieron según los casos mediante ordenanzas y edictos. El Edicto de Ammișaduqa ${ }^{40}$, es el ejemplar mejor conservado de los que disponemos, redactado durante el primer año de su reinado ${ }^{41}$. En cuanto a su estructura externa, se asemeja a una colección legal reducida ${ }^{42}$. Del Edicto Ammișaduqa solo se conserva el Preámbulo, aunque muy fragmentado y 22 de sus disposiciones ${ }^{43}$. Estos decretos ${ }^{44}$ fueron redactados por funcionarios especializados en cada uno de los apartados en que se divide el texto. Según parece, la finalidad de este Edicto promulgado por Ammișaduqa fue la condonación de las deudas contraídas por la población con la administración y con personas pertenecientes al ámbito privado.

40 Décimo monarca de la Dinastía I de Babilonia que reinó durante los años 1646 a 1626. Mediante este edicto, Ammișaduqa restablecía la justicia al País y lograba devolver a su pueblo por la senda recta. Este texto de carácter legislativo se publicó en el primer año de su reinado y se ha conservado en dos ejemplares; el denominado, A (British Museum: BM 80289). Tablilla babilónica antigua en F.R. Kraus (1984) pl. 2; p. 164). Contiene una columna y era la primera de un grupo de tablillas que recogían el texto íntegro del Edicto. El ejemplar, B (Eski Sark Eserleri Müzesi, Estambul: Ni. 632). Tablilla babilónica antigua, Kraus (1984), pl. 3-6; pp. 165-166). Contiene una tablilla mucho más extensa compuesta por 6 columnas, que recogían todo el texto, aunque se encuentra en un estado bastante fragmentado. Acerca de las ediciones e información bibliográfica. vid, los trabajos de F. R. Kraus (1984) pp.164-166, 178-181 y 249-257.; D. Charpin (1987) pp. 36-44.

41 Ammișaduqa publicó otro edicto, diez años después. La frecuente proclamación de «edictos de equidad» provienen de Isin, Larsa, Ešnunna y Babilonia.

${ }_{42}$ Las diferencias en cuanto a la fórmula dominante de las Leyes de Ex̌nunna con respecto al «Código" de Hammurabi, son visibles. Si en el $(\mathrm{CH})$ es la sentencia casuística en torno a la inclusión de la conjunción condicional «Si...», la fórmula que predomina, sin embargo, en el Edicto de Ammișaduqa es la decisión innegable llevada a cabo sobre una persona concreta, se presenta en una oración de relativo, por ejemplo, los párrafos 16 «la tabernera de las tierras de pastos que [...]», 17 «La tabernera que haya fiado [...]» y 18 «La tabernera o el mercader que, mediante [...]».

${ }^{43}$ En ellos se recogían hasta ocho apartados: 1) anulación de deudas privadas a través de los préstamos. 2) renuncia del rey a cobrar los retrasos producidos por la tardanza en la recogida de la cosecha de cebada, en concreto de la provincia de Suhum. 3) Renuncia del monarca a cobrar los retrasos de cebada y plata de las tabernas del campo. 4) Renuncia de la tabernera a recobrar préstamos de cebada y cerveza. 5) Reducción de los impuestos a dos categorías de soldados; del redûm, en sumerio, AGA.UŠ, UKU. UŠ y del ba irum 6) Rescate de familiares a consecuencia de préstamos o deudas. 7) Prohibición a los funcionarios de obligar a las personas a pagar feudo y, a realizar trabajos a cambio de anticipos de jornal.

${ }_{44}$ Conocidos con el término acadio de me/išarum «justicia», «rectitud», palabra que derivaba del verbo ašārum/ešērum (i) «estar en orden», «ir derecho»; «prosperar». La traducción más exacta de este vocablo sería el de «equidad». En opinión de J. Sanmartín (1999) p. 188 «la finalidad de un edicto era ideológica y a la vez práctica (...). vid. R. Jiménez Zamudio (2002) pp. 164 y 164. En síntesis, los edictos de «gracia» representarían la capacidad por parte del rey de volver a poner en marcha, el restablecimiento del orden de su comunidad para alcanzar la mayor armonía y, como consecuencia de ello, la prosperidad de la misma. A propósito de la justicia en Mesopotamia, vid. E. Nardoni (1993-1994) pp. 193214.; J. J. Filkelstein (1970) pp. 243-253. 
Los castigos recogidos en el Edicto de Ammișaduqa, impuestos por la autoridad para aquellos que infringen las normas son duras, al incluir la pena capital hasta en cinco de sus decretos (4, 6, 7, 18 y 22). Según parece este Edicto sigue la misma línea de actuación que el «Código» de Hammurabi ${ }^{45}$.

En cuanto a la estructura temática del Edicto de Ammișaduqa, los decretos que atañen a la sābītum, se enmarcan en los siguientes apartados: impagados, en el decreto (16), fiar productos a otra persona, en el (17) y falsedad de documentos, en el (18).

\subsubsection{Transliteración y Traducción ${ }^{46}$}

Decreto 16: B. Col. V, II. 5-10

5) MUNUS LÚ KÚRUN.NA ${ }^{47}$ na-we- $e^{48} 6$ ) ša KÙ.BABBAR še-e LÚ KÚRUN.NA a-[n]a [É.G]AL 7) i-ša-aq-qá-lut9 aš-šum ša[r]-rum mi-ša-ra-am ${ }^{50}$ 8) a-na ma-tim iš-ku-

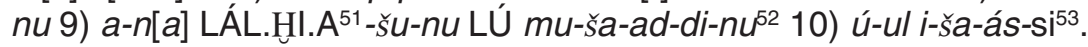

Con el propósito de ayudar a la comprensión del texto se ofrece dos posibles traducciones:

(A) la esposa del tabernero del campo que haya pagado al Palacio la plata de la cebada del tabernero, puesto que el rey ha dispuesto la remisión de deudas para el país, el recaudador no reclamará sus retrasos.

La mujer del tabernero del campo de pastos la cual paga al Palacio la plata de la cebada del tabernero, puesto que el rey ha dispuesto la justicia sobre el país; el recaudador no podrá reclamar sus atrasos.

45 El articulado empleado en el Edicto de Ammișaduqa conserva un prototipo poco innovador con respecto al del Código de Hammurabi. Un estudio pormenorizado del texto deduce una clara repetición con respecto al de Hammurabi. Cf. J. Sanmartín (1999) p. 191.

46 Vid. F. R. Kraus (1984) p. 164 (texto cuneiforme); pp. 178-181 (transliteración y traducción) y pp. 249-257 (comentarios y notas).; J. Sanmartín (1999) p. 198 (traducción).

47 Literalmente, significa: «la mujer del que hace las bebidas alcohólicas». Cf. J. Sanmartin (1999) n. (79) en p. 205.

48 nawû(m) V. namû(m): «pasto», «tierras de pastos». F. R. Kraus (1984) p. 179 traduce «Eine Schankwirtin des Sommerweidegebeites» "Una tabernera de los terrenos de pastoreo de verano».

$493^{\underline{a}} \mathrm{sg}$. masc. del presente $(\mathrm{G})+/ \mathrm{u}$ / de subjuntivo de saqālum $(\mathrm{a} / \mathrm{u})$ «pesar», «pagar», «ingresar». En cuanto a la interpretación de esta parte del texto, vid. J. Sanmartin (1999) n. (81) en p. 205.

50 El termino mī/ēšarum traducimos por «remisión de deudas», «la vuelta de las cosas a su estado originario». vid. E. Nardoni (1993/4) pp. 193-214 y más concretamente, pp. 195-198.; N.P. Lemche (1979) p. 16.

51 LÁL. Sumerograma que hace referencia a todo aquello que queda pendiente: «débito», «deuda», «carencia», déficit». Y con su plural HI.A aquellas cosas que quedan pendientes. Es decir, los atrasos en los pagos.

52 mušaddinum Participio (S) de nadānu(m) (i). (G) «dar», «entregar». En (ঙ̌) «hacer dar /entregar». Aquí traducimos por recaudador.

53 Verbo principal del texto. Presente $(G)$ de $\operatorname{sasû}(m)(-i)$ «reclamar», «apelar», «convocar» 3" sg. masc. + partícula negativa -ūl que expresa una orden sin mandato. 
Decreto 17: B. Col. V, II. 11-13

11) MUNUS LÚ KÚRUN.NA ${ }^{54}$ [š]a KAŠ ù še-am i-qí-pu ${ }^{55}$ 12) mi-im-ma [š]a i-qípu 13) ú-ul ú-ša-ad-da-an ${ }^{56}$.

La tabernera que cerveza o cebada ha confiado a alguien, nada de lo que confió no entregará.

Decreto 18: B. Col. V, II. 14-16

14) MUNUS LÚ KÚRUN.NA ù DÀM.GAR $\left.{ }^{57} 15\right)$ [š]a i(?)-na(?) [k]u-un-u[k-kp̉8 $] a$ $k[i]-i t-$ tim $^{59}$ 16) $[\mathrm{x} \times \mathrm{x} \times \mathrm{x}] \times[\mathrm{x} \times \mathrm{x}] \times \mathrm{i}-\mathrm{ma-a}-a[t]^{60}$.

\section{La tabernera o el mercader que en un documento sellado no verdadero [...] morirá}

\subsection{Las Leyes Asirias Medias: Descubrimiento, datación cronológica y descripción externa}

Entre los siglos XIV y XII a. de C., algunos reyes asirios ${ }^{61}$ realizaron una política expansionista que trajo como resultado un desarrollo de la economía y una estabilidad social. En este espacio de tiempo se fechan las denominadas Leyes Asirias Medias $^{62}$. El estilo de este corpus legislativo es casuístico y tienen que ver con el derecho de la propiedad del sector privado. Los párrafos de los artículos introducen la conjunción condicional šumma «sì al igual que sucede en las Leyes de Ešnunna y el «Código» de Hammurabij3. Se han conservados diversos ejemplares,

54 J. Sanmartín expone que el texto hace referencia a toda tabernera, no sólo a la que ejerce su función en «las tierras de pastos».

$553^{\underline{a}}$ sg. masc. del presente $(G)+/ u$ / de subjuntivo de II qâpu(m) (-ī-) «confiar (algo a alguien)». vid. J. Sanmartin (1999) n. (84) en p. 205.

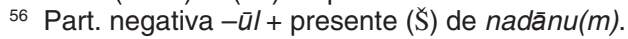

57 Como apunta J. Sanmartín (1999) n. (86) p. 205, la tabernera y el mercader eran las dos profesiones que monopolizan la concesión de crédito en mayor o menor proporción.

58 Kunukku(m) (NA.KIŠBB) «sello», «documento sellado».

59 Kittu $(m)$ Fem. de Kīēnu $(m)$ «recto», «justo». Como nombre «verdad», «equidad», «justicia».

$603^{\mathrm{a}} \mathrm{sg}$. masc. del presente $(\mathrm{G})$ de $\operatorname{mâtu}(m)(-\bar{u}-)$ «morir». El estado bastante fragmentado del texto, impide conocer exactamente la causa que justifica el máximo castigo para la tabernera y el comerciante. 1208).

61 Especialmente, Aššr-uballiț I (1368-1328), Adadnirari I (1305-1274) y Tukulti-Ninurta I (1244-

62 Redactadas en trece tablillas, doce de las cuales fueron exhumadas en la ciudad de Ašsur (la actual Qala`at Šerqat) durante los años 1903 y 1914. Este lote de tablillas son copias fechadas en torno al siglo XII a. de C., y fueron encontradas en las proximidades de la llamada Puerta de Samaš. Según J. Sanmartín, en dicha puerta debió de funcionar un «tribunal». Algunos ejemplares fueron redactados y compilados para ser empleados como ejercicio de entrenamiento de jueces y escribas.

63 Para J. Sanmartín, las Leyes Asirias Medias constituyeron recopilaciones escolásticas de material legal, proveniente de la voluntad legislativa regia o susceptible de ser asumido por ella, y la influencia babilónica es notable como casi todo lo asirio. Toda la legislación paleobabilónica era muy conocida y estudiada en la Asiría de los siglos XIV al XII a. de C. De ahí las numerosas copias realizadas de estas tablillas. 
identificados con las letras de «A» $a$ «O $\mathrm{O}{ }^{64}$. De todas ellas, las denominadas Tablillas «A», «B»y «C+G» permiten una lectura legible y coherente, sin embargo, la Tablilla A se ha conservado prácticamente completa.

La mujer es el tema que más incide en las Leyes Asirias Medias. En cuanto a su artículo decimocuarto, incluido en su segunda columna, alude a la taberna y se encuadra dentro del apartado del Derecho matrimonial ${ }^{65}$.

\subsubsection{Transliteración y Traducción 6}

Ley 14: A. Col. II, II. 30-40

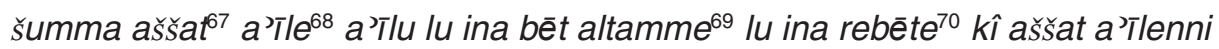
$\bar{l} d e^{73}(\ldots)^{72}$.

\section{Si la esposa de un hombre (con) otro hombre en la taberna o bien en la plaza como esposa de un hombre ha conocido (...)}

64 La denominada «Tablilla J» es por su caligrafía la más antigua de todos los ejemplares.

65 Las 59 disposiciones legales que contiene las Leyes medio-asirias presentaban diversos temas a tratar, entre los cuales se encontraban: robos, blasfemias, brujería, propiedades matrimoniales, depósitos, acoso y ofensas sexuales. El artículo decimocuarto se centra en el apartado de adulterio y fornicación.

66 Vid. O. Schröder (1920) Nr. 1 (= VAT 10000) p. 3 (inscripción cuneiforme), col. II, II. 30-40; L. Cagni (1971) pp. 76-81 (transliteración y traducción).; W. Mayer (1971) (para la Gramática del Medio Asirio).; Martha T. Roth (1995) p. 158 (transliteración y traducción).; J. Sanmartín (1999) p. 220 (traducción).

67 ašsat, constructo de ašsatu $(m)$ (bab., as.), en sumerio, Mí.DAM «mujer», «esposa». Las leyes distinguían entre los conceptos de mujer casada, ašsatum y de la mujer sin atributos, sinništum.

68 aīle/u, es la forma asiria, en sumerio LÚ. El término babilonio, awī/ēlum (amēlu) «hombre»., en el sentido de designar a una persona jurídicamente libre, es decir, que gozaba de todos los derechos inherentes a su categoría social.

69 bēt con contracción de -a- en -e- en vez de -ī-; bēt = bab. bīt < ${ }^{*}$ baitu «casa» + aštammu, altammu, debido a que, gramaticalmente, durante el período medio-asirio, št $>\mid t$, con las acepciones de «taberna», «hospedería». En sumerio, MA[ES.DAM].

70 rebē/itum «plaza», «calle». En sumerio, SILA.DAGAL(.LA). La taberna, la calle y la plaza eran considerados por los mesopotámicos lugares abiertos y por lo tanto zonas idóneas para la prostitución. De ahí que, la presencia de la esposa en estos lugares se la pudiese asociar a la conducta de la prostituta, lo que incidiría en la posible ignorancia de su estado civil por parte del fornicador. La ignorancia por parte de éste fue considerado por los jueces un atenuante. Solo es culpable en caso de que lo conociese. El marido tenía el derecho de hacer con su esposa lo que quisiese, literalmente, kî libbišu «según su corazón". nā'ikānum<niākum era el término acadio que designaba a la persona que tenía relaciones sexuales fuera del matrimonio.

$713^{\text {a }} \mathrm{sg}$. masc. del pretérito idû, edû (->; -e) «conocer», «saber».

72 Vid. M. T. Roth (1995) p. 158 (transliteración y traducción).; J. Sanmartín (1999) p. 220 (traducción). 


\section{OTRAS CATEGORÍAS SOCIALES EN RELACIÓN CON LA SABITUM (MÍ.KURUN.NA)}

\subsection{SAG.ÌR/wardum y GÉME/amtum}

La situación de los esclavos en Mesopotamia dependía de diversas circunstancias. A lo largo del período paleobabilónico, el escriba continuó empleando el sumerograma para referirse a los esclavos. Así, en el artículo 15 de las (LE), SAG.İR ${ }^{73} /$ wardum «esclavo» y GÉME/amtum «esclava», "sierva». La situación de esta categoría social sufrió con el paso del tiempo una importante modificación dentro del ámbito doméstico. La labor doméstica corrió a cargo de esclavos o bien, en mucho mayor grado de personas que gozaban de una libertad restringida (siervos). Según la información que nos ofrece los contratos matrimoniales fechados en época paleobabilónica, las relaciones maritales de las mujeres pertenecientes a categorías sociales diferentes determinó una encrucijada de caminos entre la nadītum y la šugē/itum y la nadītum y la amtum ${ }^{74}$.

Según la información del parágrafo 15 de las (LE) sorprende que, los esclavos como las esclavas pudieran disponer de bienes personales, incluso en algunos casos en cantidades nada desdeñables ${ }^{75}$. Sin embargo, se encontraban sometidos a restricciones en cuanto a su capacidad legal de actuar, al tener prohibido la entrega de cualquier tipo de producto a las tamkarū y a las sabitū. El texto también omite si los esclavos y esclavas podían hacer entrega de estos productos a otros estamentos sociales. Por otra parte, la omisión de sanción alguna tanto para los que daban como para los que recibían, induce a pensar en la ausencia de graves consecuencias para ambas artes. Tampoco recoge información con respecto a la institución social a la cual pertenecían estos esclavos: civil (palacio), religioso (templo) o privado. Sin embargo, a consecuencia del esplendor y el lujo adquirido a través de sus respectivos negocios por parte de mercaderes, taberneras y otros oficios pertenecientes al ámbito privado, pudieron adquirir siervos domésticos que gozaron de una libertad restringida.

${ }^{73}$ Este sumerograma se compone de SAG, seudolograma RA.SI, en acadio, rē/Ǐšu, con varias acepciones: 1) «cabeza», «comienzo», «almena», «cima»; «esclavo». 1) «de primera calidad, primero, de primera clase» junto a İR, en acadio wardum «esclavo, siervo, súbdito» en acadio, wardum, "esclavo», «criado». El empleo de este seudolograma conllevaba de manera implícita la idea subliminal de hacer referencia a un esclavo con una cierta distinción. A continuación el escriba emplea el segundo sumerograma, İR, en acadio, wardum, término que tiene las mismas acepciones: "esclavo», "siervo», «súbdito».

${ }^{74}$ En cuanto a la naditum y la sugetum y la nadītum y la amtum. En las dos primeras categorías ambas tenían ciertas peculiaridades que las diferenciaban del resto, compartían su relación con el gagûm. Las dos habían sido consagradas a él. La sugetum en subordinación con respecto a la nadītum, en algunos casos pudieron ser hermanas. La šgetum, sacerdotisa dedicada a funciones subalternas de culto podían como las naditū contraer matrimonio. Sin embargo, las naditū, "yerma» se la prohibía engendrar sus propios hijos. La solución a tenor de estos contratos matrimoniales era que la naditum pudiese adoptar o destinar una šugetum o una antum para alcanzar este fin. vid. M. Rosa Oliver (2006) pp. 86-91.

75 La expresión adi ma-di ?/ți-im presenta una lectura e interpretación incierta. Tal expresión acadia deriva del verbo ma'ādu (i) «ser numeroso», «grande». 
Los esclavos ocuparon el último escalafón de la sociedad y se nutrían de población indígena, por deudas contraídas, o bien de extranjeros hechos prisioneros en contiendas militares. En cuanto a los esclavos domésticos, eran más escasos y formaban parte de las familias de los awilū, ciudadanos libres, sin deudas. Dentro de esta categoría social se encontraban los tamkarū.

\subsection{DAM.GÀR/tamkārum}

El Palacio y el Templo fueron las dos grandes unidades económicas que se constituyen a lo largo de la historia en Mesopotamia. Fueron las encargadas de organizar los envíos comerciales por medio de su propia red de mercaderes. Ambas instituciones acumularon enormes cantidades de riquezas que, unido a su gran capacidad de planificación, les permitió organizar toda clase de envíos comerciales. Al mismo tiempo, el palacio y el templo fueron los receptores de la mayor parte de productos que necesitaba la corte y los diversos actos que confería el culto.

A comienzos del segundo milenio, los DAM.GÀR ${ }^{76}$ empiezan a organizarse en «gremios». Aunque continúen trabajando para la administración del Estado, irán progresivamente alcanzando un mayor grado de independencia con respecto a las instituciones oficiales. El tamkārum recibía por su trabajo una cantidad de «dinero» (generalmente, en metal) que, generalmente, empleó para realizar actividades comerciales por su cuenta. El tamkārum, negociante y banquero, fue considerado en un principio, un mercader itinerante, que se dedicaba a la venta, compra de bienes de consumo, además de prestar «dinero». Posteriormente, una vez asentado se dedica a vender al por mayor, a financiar algunas empresas, o bien, a prestar dinero a otros colectivos sociales que necesitaban de sus servicios. El tamkārum pertenecía a una organización oficial conocida con el nombre de wakil tamkāri. Esta institución se encargaba de llevar a cabo funciones administrativas, recaudación de impuestos y, en ciertas ocasiones, de realizar algunas compras por encargo del Palacio. El tamkārum, también se dedicaba a negociar el rescate de prisioneros, especialmente, militares de alta graduación. Para esta función, el tamkārum se trasladaba hasta las inmediaciones de los pasos fronterizos, lugar idóneo para realizar el canje. También se dedicó al comercio de esclavos, negocio muy lucrativo por la gran demanda que existía en todas las ciudades mesopotámicas.

Con todos estos cambios, los tamkarū pasaron a operar con mayor nitidez al margen del Palacio, el Templo y las Comunidades rurales. Sus frecuentes viajes comerciales les proporcionaron importantes beneficios que fueron de nuevo invertidos en diversas operaciones mercantiles. El creciente aumento de sus rentas les permitió alcanzar una situación de privilegio con respecto a la administración

${ }^{76}$ El escriba continúa empleando en el artículo 15 de las (LE) empleando el correspondiente sumerograma, DAM.GÀR en acadio, tamkārum para referirse al «mercader». 
estatal que se tradujo en la exoneración de algunas cargas fiscales, no extensible a otros estamentos sociales.

\section{MUJERES QUE DESEMPEÑARON PROFESIONES FUERA DEL ÁMBITO DOMÉSTICO}

\subsection{LUKUR/nadītum}

Las naditūt7 fueron consideradas sacerdotisas especiales de alto rango con actuación económica. De vida semi-conventual, la mayoría de estas mujeres provenían de familias ricas y poderosas. Estaban unidas al templo pero administraban sus propios bienes e intervenían en negocios, transacciones y préstamos. Vivían en el templo, en el área del gagûm ${ }^{78}$. Estas sacerdotisas tenían la obligación de permanecer célibes. Sin embargo, había diferencias, según dependiesen de una divinidad u otra. Así, a las naditū consagradas al dios Šamaš las estaba prohibido casarse, en cambio, a las consagradas al dios Marduk, las estaba permitido. No obstante, en cualquier caso, se las prohibía concebir hijos.

La nadītum dispuso de los mismos derechos que los hijos varones, por ejemplo, a la hora de heredar, impensable para otras categorías de mujeres de la época. La entrada de la nadītum en el gagûm permitió consolidar una alianza entre sus respectivas familias y el templo. Con ello, las familias de las naditū evitaban la fragmentación de su respectivo patrimonio, ya que, a la muerte de estas sacerdotisas, el patrimonio adquirido por ellas era de nuevo incorporado al seno familiar. El artículo 110 del $\mathrm{CH}$ hace alusión tanto a la nadītum como a la ēntum (NIN.DINGIR $)^{79}$ al prohibirlas tanto la entrada como la apertura de una taberna. La pena a la que se sometían era la muerte en la hoguera. Este tipo de castigo por fuego solo aparece una vez más en el $\mathrm{CH}$, en su artículo 157 al tratar del incesto de un hijo con su madre. Al ser consideradas las tabernas como lupanares, el legislador castigaba la inmoralidad de las sacerdotisas.

\section{2. (MÍ.KURUN.NA)/sābītum}

Para la mujer mesopotámica que había alcanzado la pubertad y sin apenas oficio ni beneficio, la quedaba pocas opciones más allá del matrimonio. La sociedad patriarcal en la que se asentaba la sociedad en Mesopotamia, impedía que se cre-

77 Vocablo acadio con el significa «la baldía», «la sin cultivar», en sumerio, LUKUR=MUNUS/Mí-ME. Consideradas sacerdotisas de alto rango que debían permanecer sin hijos.

${ }^{78}$ Vocablo acadio, en sumerio, GÁ-GI.A, GAGIA, «claustro». Edificio o sección del distrito del templo reservado exclusivamente para ellas.

79 ēntum Fem. de enum. Logograma NIN.DINGIR «Señora del dios». Sacerdotisa de alto rango que junto a la nadítum solían vivir fuera del gagûm. Esta categoría de mujer sacerdotisa también se encuentra atestiguada en la correspondencia femenina de Mari (ARMX, 126 r. I.5). 
ara un ambiente propicio para que la mujer se pudiese alcanzar algún destino profesional, más allá de las labores propias de su género, en torno al hogar y los hijos. Por lo tanto, la sociedad establecida las impedía abrirse camino en igualdad de condiciones con respecto a los hombres. No obstante, a pesar de todos los contratiempos, surgieron mujeres valientes y luchadoras, capaces de abrirse camino con las pocas opciones que la vida las otorgaba.

Una prueba de ello, lo tenemos en las mujeres que ejercieron el oficio de taberneras, provenientes de los estratos sociales inferiores y con una categoría profesional más bien baja. En su establecimiento la sābītum fabricaba cerveza con distintos grados de alcohol y otras bebidas (aguardiente de dátiles y diversos brebajes). Desde el principio de los tiempos históricos se conocía la elaboración de distintos tipos de cerveza, por ejemplo («cerveza negra», «cerveza roja», «cerveza fermentada», etc.). Asimismo, gestionaba la reventa de la cerveza perteneciente a otros miembros de la sociedad, negocio que la aportaba un beneficio extra. Además, comerciaba con diferentes tipos de productos y realizaba préstamos en especie (cebada, grano) o, en metálico (generalmente, en plata). La tabernera vendía su cerveza a los habitantes y aldeanos que acudían a la ciudad. En numerosas ocasiones ejerció de prestamista, ofreciendo créditos ${ }^{80}$ en tiempos de carestía. Según las Leyes de Ešnunna, tanto los tamkārū como las sabitū no podían aceptar mercancías de los esclavos, ni tampoco conceder créditos a menores y esclavos. En definitiva, el negocio de compra-venta de bebidas alcohólicas le generó a la sābītum su bienestar económico y, en cierta forma, social.

La taberna fue considerada por los mesopotámicos un centro social que permitió la existencia de un comercio en torno al sexo. Allí se dieron cita personas pertenecientes a diferentes profesiones, algunas de dudosa reputación y que eligieron este establecimiento público para beber tranquilamente, charlar de temas relacionados acerca del oficio que ejercían, o bien, de asuntos familiares y, también como no, de las quejas por los impuestos que imponía el Estado. Por diversos motivos, las tabernas fueron mal vistas por los ciudadanos (awīlum) e instituciones. Las tabernas solían estar ubicadas, preferentemente, a las afueras de la ciudad, próximas a los cruces de caminos por donde transitaban las caravanas y, finalmente, en el puerto de la ciudad (kārum).

Estas tabernas estuvieron bajo la protección de la diosa Inanna/Ištar y solían estar decoradas con contenidos de carácter erótico. La administración del Palacio permitió la creación de estos establecimientos públicos, a pesar de los inconvenientes que conllevaba este tipo de negocios. Las autoridades públicas pensaron que si no legalizaban estos locales, los clientes potenciales (mercaderes y marineros) provenientes de otros lugares pasarían de largo y los buscarían en la pró-

80 En las leyes de Ešnunna y «Código» de Hammurabi, el interés máximo que podía pedirse por un préstamo era de un $20 \%$, si este préstamo se realizaba en plata, y un $331 / 3 \%$ si era de cebada. No sabemos si este era el patrón tipo tanto para los tamkārū como para las sabitū. En el «Código» de Hammurabi, el deudor podía pagar con cebada o con otro tipo de mercancías si no se encontraba en situación de saldarla con plata. vid. J. Klíma (1983) pp. 165-166. 
xima ciudad. A cambio, el Palacio a través de la administración cobraba a la tabernera una tasa que no viene tipificada en los textos aquí recogidos.

La prostitución fue consentida en mayor o menor medida por los poderes públicos y controlada por funcionarios, lo cual contribuyó a mantener la paz, puesto que, su prohibición supondría el aumento de otros delitos, caso de las violaciones y, por lo tanto, incidiría de forma directa en el aumento de la inseguridad ciudadana. Las tabernas fueron también lugares de encuentro de personas de diferentes lugares, originándose una basta mezcolanza de palabras y expresiones tomadas de diferentes lenguas, acompañada de signos y gestos. El interior de estos establecimientos públicos fue discretamente vigilado por funcionarios, con el fin de abortar posibles planes conspirativos contra el Palacio.

Como ya hemos apuntado, el carácter bilingüe de los escribas quedó manifiestamente reflejado en los textos, al utilizar indistintamente, tanto el sumerograma, Mí.KURUN.NA, como el acadiograma, sābītum.

\section{DELITOS COMETIDOS POR LA SABITUM (MÍ.KURUN.NA)}

Algunos artículos recogidos en lo textos legales del período paleobabilónico sacan a la luz la importancia económica y social de las tabernas. La mujer que dirigía este establecimiento se encargaba, entre otros asuntos, de la venta, de la elaboración de bebidas fermentadas, de comercio de algunos productos y de participar en transacciones a crédito ${ }^{81}$. Algunas de sus actividades fueron parecidas a las del comerciante, lo que explicaría la yuxtaposición de estas dos categorías profesionales en ciertas normas legales ${ }^{82}$. Una parte de la taberna estaba destinada a servir de almacenes, y por lo tanto, sometida a una reglamentación particular, al tener que pasar por las formalidades propias de un registro de la propiedad. A fin de obtener la correspondiente licencia de explotación de su establecimiento público, la tabernera tenía que proveerse de fondos para poder pagar la correspondiente tasa al Estado, es decir al Palacio ${ }^{83}$.

El emplazamiento de las tabernas en los arrabales de la ciudad, encrucijadas de caminos, puertos fluviales y canales, tuvo una incidencia directa sobre la fama que adquirieron dichos establecimientos públicos. La implantación geográfica de las «casas de la cerveza» se encontraba en el mismo espacio público donde se daba la prostitución. Las meretrices realizaban su trabajo en las mismas puertas (KÁ/bābtum) de las tabernas y calles aledañas. Sin embargo, la diferencia que separa las actividades de la tabernera y el de la prostituta no es siempre claramente percibida. Estos lugares protegían a todo tipo de individuos poco recomendables

${ }^{81}$ La sābītum y el tamkārum, son dos de los oficios que aglutinaron la concesión de qiptum «crédito». La sābītum concedió préstamos en mayor o menor medida a sus clientes más asiduos. Igualmente, debió anotar aquellos artículos que no habían sido pagados.

82 S. Lafont (1999) n. (1) en p. 413.

83 S. Lafont., ibid., n. (3) en p. 414. 
(fugitivos, delincuentes, amotinadores). En este ambiente no es sorprendente que, la producción y administración de bebidas alcohólicas por parte de la tabernera alcanzase una mala reputación. El predominio de las mujeres en este sector económico a lo largo del período paleobabilonio estuvo estrechamente interrelacionado a un factor religioso ${ }^{84}$ y a un factor sociológico ${ }^{85}$.

El artículo 108 del $\mathrm{CH}$ se limita a mencionar un «gran peso» para señalar el fraude cometido por la tabernera que no se sirvió de los pesos ajustados a las normas establecidas por Hammurabi. Una infracción similar aparece descrita en el decreto número 18 del EAS que incriminaba el fraude realizado por la tabernera o el mercader al emplear un falso documento. Las lagunas del texto impiden conocer cual fue la naturaleza exacta del timo y que tipo de muerte merece.

En opinión de S. Lafont ${ }^{86}$, el legislador se interesa por este tipo de delitos en cuanto a la pesada, ya que, el delito no se encontraba aparentemente en la demanda de dinero, que no se consideraba ilegal, sino en la cantidad exigida de metal porque es excesiva. El fraude podía cometerse también con otros valores de intercambio en el momento de la pesada. El artículo 108 del $\mathrm{CH}$ manifiesta una preocupación de las autoridades por reprimir los fraudes, en un ámbito donde eran bastante frecuentes y difíciles de probar. Por ejemplo, si el cliente ignoraba la existencia de tarifas con respecto a los pesos, podía ser burlado fácilmente por la tabernera, especialmente. Así les ocurría a los extranjeros no residentes o ciudadanos de otras ciudades como lo registra el artículo 41 de las LE. Hammurabi, a través del artículo 108, quería proteger al ubarum, al napțarum y al mudûm contra los fraudes de la tabernera en la reventa de sus excedentes de cerveza. De esta manera, trataba de garantizar la seguridad de las transacciones y, al mismo tiempo, favorecer los intercambios económicos por los negociantes ambulantes y otros viajeros. La pena impuesta a la tabernera por este tipo de delitos era la ordalía ${ }^{87}$.

\section{CONSIDERACIONES FINALES}

Desde el punto de vista lingüístico, el sumerio siguió empleándose en los textos de carácter legal, a pesar de que ya no volvería a ser la lengua oficial en ninguna de las cancillerías. Durante la época del Antiguo Babilonio los escribas fueron

${ }^{84}$ La fabricación de cerveza estaba bajo la protección de las diosas, Ninkasi y Siri. vid. S. Lafont, ibid., n. (9) en p. 415.

85 Las formas de comercio relacionadas a las taberneras estaban asociadas a su género. Con Hammurabi primero y de una forma más notoria con Ammișaduqa, se van a ir modificando las estructuras sociales en todo el imperio. Tales cambios provocarán la evolución del tabernero que escapa de la competencia de las mujeres. Cf. L. F. Hartman-A.L. Oppenheim (1951) p. 12.

86 S. Lafont, ibid., n. (3) en p. 419.

87 ú-ka-an-nu-گ̌i-ma «(se) lo probaran»; es decir, se necesitaba la presencia de testigo(s). Sobre la pena de muerte por ahogamiento, véanse los artículos del $\mathrm{CH} 129,133 \mathrm{~b}, 143$ y 155 . En el derecho mesopotámico, era considerado el «juicio del dios». Este tipo de juicio, ponía en manos de la Naturaleza la última decisión por medio del «Río divinizado» (nārum/ID ${ }_{2}$ ). 
bilingües y ello quedó manifiestamente reflejado en la legislación al emplear indistintamente ambas lenguas en sus escritos.

La idea predominante durante el período paleobabilónico era que el rey se presentaba como «justo» mediante la publicación de una normativa de leyes, encuadradas dentro de un «Código» que seguía una tradición que se remontaba a UrNamma de Ur. Con esta práctica, los reyes legisladores de la primera mitad del segundo milenio, vendrían a resaltar la sabia y eficaz dirección de su gestión. El corpus de leyes que contenían tanto códigos, edictos y decretos, vendría a ser una demostración analítica de que la justicia reinaba en el país, al recoger en ellas, una solución a los problemas que la sociedad en cualquiera de sus ámbitos generaba. Por ejemplo, y ateniéndonos al tema que nos ocupa, si una tabernera rebajaba el valor de la cerveza la pena era tirarla al agua, en cambio, si una tabernera suministraba 1 cántaro de cerveza a cuenta la tarifa eran 50 qû de cebada, y así sucesivamente. En este conjunto de disposiciones se encuentra la idea del «buen gobierno", en el que todo está ordenado con arreglo a unas normas equitativas, sin dejar pequeñas fallas para la prevaricación y la arbitrariedad. Un Estado próspero y «feliz» se basaba en la idea de la justicia, en virtud de las normas existentes. El gobierno que no aplicase estas disposiciones legales estaría conduciendo a su sociedad a un estado caótico.

En cuanto a las leyes de Ešnunna, incluían una lista de precios, pero, según parece, no son precios nuevos, más o menos favorables a los anteriores, ni tampoco se trataba de precios máximos o mínimos, sino que se trataba sencillamente de precios «justos» y estables.

Por lo que respecta al patrón del intercambio, la sociedad paleobabilónica se basaba en dos tipos de productos, la cebada y la plata: tanta cantidad de cebada igual a tanta cantidad de plata. La forma en que la sociedad de Ešnunna, Babilonia se consideraba próspera se medía por medio de una alta productividad interior y una afluencia de mercancías provenientes del exterior.

La separación entre lo público y lo privado en la sociedad paleobabilónica es bastante difícil de discernir, si entendemos lo privado como aquello que se identifica con lo individual y lo público con lo colectivo. Sin embargo, a través de la legislación mesopotámica, se aprecia la presencia activa de un sector de la sociedad que gestionaba sus negocios al margen del Palacio. Dentro del mismo se encontraban las taberneras, los mercaderes y las categorías más altas de las sacerdotisas. Estas elites sociales alcanzaron un nivel de desarrollo social y económico muy destacado. Sin embargo, el Palacio siguió conservando en sus manos una alta capacidad de organización de la vida económica por lo que respecta a la hora de regular precios y salarios. Este fenómeno se aprecia de una manera nítida cuando se producía una subida continúa de precios que afectó de manera directa a las categorías sociales más bajas.

Hammurabi, nada más acceder al trono tuvo que solucionar este grave problema y para ello hubo de intervenir en los diferentes sectores de la vida social y económica. Así, reguló la actuación de los granjeros, aparceros, obreros agrícolas 
y fijó los salarios, el precio del alquiler de los animales, las bebidas alcohólicas y la organización del aprendizaje artesanal.

En definitiva, si exceptuamos la breve referencia a la taberna que registra el artículo décimo-cuarto de las Leyes asirias medias, sin especificar si la dirigía una mujer o un hombre; podemos afirmar que, los textos posteriores al 1500 a. de C., no recogen más la presencia de la sābîtum. La figura de la sābītum se centró exclusivamente en las recopilaciones jurídicas de época paleobabilónica, cuando el oficio de tabernera fue considerada una profesión exclusivamente femenina. Esta independencia que consigue alcanzar no sólo la tabernera a través de su oficio, sino a otras mujeres pertenecientes a otras instituciones civiles y religiosas, las permitirán disponer de pequeños espacios de privacidad y «libertad», aunque con limitaciones. El Palacio será la primera institución civil que tenga en cuenta la importancia que fueron adquiriendo las taberneras en la sociedad paleobabilónica. Por medio de su aparato administrativo y judicial, legisló acerca de sus negocios, de los posibles delitos de índole profesional y religioso en los cuales podía incurrir, además de su correspondiente castigo.

Si nos atenemos estrictamente a la literalidad de los artículos 108, 109 y 110 del $\mathrm{CH}$, queda patente la extremada dureza que aplica contra la sābītum y otras mujeres que se encontraban fuera del ámbito doméstico, al castigar delitos menores con penas draconianas. Las colecciones de leyes aparecidas durante la época paleobabilónica, son del todo incompleto, ya que, en ningún momento pudieron abarcar todas las necesidades que la sociedad demandaba. Los textos legales aquí recogidos se reduce, grosso modo, a normas del Derecho de propiedad, de familia y del Talión. El «Código» de Hammurabi se quedó en un intento fallido, y solo recopiló legislaciones de otras ciudades con la aportación de pequeñas modificaciones. Los supuestos jurídicos-económicos que no quedaron recogidos en el $\mathrm{CH}$ quedaron fijados, posteriormente, mediante edictos, caso del de Ammișaduqa y otro tipo de ordenanzas.

\section{APÉNDICES}

\subsection{Bibliografía}

F. al-Rawi Sumer 38 (1982), «Assault and Battery»: Sumer 38, pp. 117-120 (=F. al-Rawi.: Sumer 40, 1984 [sección árabe], pp. 95-98.

E. Bergmann (1953), Codex Hammurabi. Textus primigenius. Roma.

R. Borges (1979), Babylonisch-Assyrische Lesestücke. I-II. Roma.

J. Bottéro (1965) 155-247. «La femme dans l'Asie occidentale ancienne» sous la dir. De P. Grimal, in Histoire mondiale de la femme. París.

$\mathrm{CAD}=$ The Asirian Dictionary of the Oriental Institute of the University of Chicago. Chicago 1955- (en curso de publicación).

L. Cagni (1971), Crestomamazia Accadica. Roma

D. Charpin AfO 34 (1987) 36-44, «Les décrets royaux à l'Époque Paléo-Babylonienne, à propos d'un ouvrage récent».

F. D’Agostino (2007), Gilgameš o la Conquista de la Inmortalidad. Madrid. 
G. Driver-J. Miles (1995), The Babylonian laws, vol. II. Londres

A. Finet, Le Code de Hammurabi. París.

J. J. Glassner (1986) 127-174, «De Sumer à Babylone: familles pour gérer, familles pour régner», sous la dir. De A. Burguière, in Histoire de la famille, vol. 1, Mondes lointains. París, 1986.

J. J. Glassner (1991), «Les dieux et les hommes, le vin et la bière en Mésopotamie ancienne», en D. Fournier y S. D'Onofrio, Le Ferment divin. París.

A. Goetze Sumer 4 (1948a) 63-102, «The Laws of Eshnunna Discovered at Tell Harmal»: Sumer 4, pl. I, II: [A]; pl. III, IV: [B].

A. Goetze (1950), "The Laws of Eshnunna», en J.B. Pritchard (ed.), Ancient Near Eastern Texts Relating to the Old Testament, Princeton, ${ }^{21995,}{ }^{3} 1969$ with Suplement, pp. 161163.

A. Goetze (1956), The Laws of Eshnunna (Annual of the American Schools of Oriental Research, 31). New Haven (pp. 187-193: [A]; pp. 194-197: [B].

R. Jiménez Zamudio (2002), Antología de Textos Acadios. Madrid.

J. Klíma (1983), Sociedad y Cultura en la Antigua Mesopotamia. Madrid.

J. Klíma (1971) RLA III 252-255, «Gesetze: A. Babylonien; Altbabylonische Zeit; 5. Die Gesetze von Ešnunna».

F. R. Kraus (1984), Königliche Verfügungen in altbabylonischer Zeit (Studia et Documenta ad Iura Orientis Antiqui Pertinentia, 11). Leiden.

S. Lafont (1999), Femmes, Droit et Justice dans l'Antiquité orientale. Contribution à l'etude du droit penal au Proche-Orient ancient. Fribourg.

F. Lara Peinado (1988), Poema de Gilgamesh Madrid.

F. Lara Peinado (2008), El Código de Hammurabi. Madrid.

F. Lara Peinado-F. Lara González (2001), Los primeros Códigos de la humanidad. Madrid.

N. P. Lemche JNES (1979), «Andurárum and Mišarum: Comments on the Problem of Social Edicts and their Application in the Ancient Near East».

Martha T. Roth (1995) 57-70, «The Law of Eshnunna», en M.T. Roth, with a contribution by H.A. Hoffner, Jr., Law Collections from Mesopotamia and Asia Minor (Writings from the Ancient World, 6). Atlanta, Georgia.

Martha T. Roth (1999) AOAT, 267, «The Priestess and the Tavern: LH 110» (Fest. J. Renger).

W. Mayer (1971), Zur Grammatik des mittelassyrischen Rechtsbuchs. Kevelaer y Neukirchen-Vluyn.

M. Molina (2001), «La cerveza de la Antigua Mesopotamia», en La cerveza en la Antigüedad. Sevilla.

E. Nardoni RB 52 (1993-1994) 193-214, «La Justicia en Mesopotamia Antigua».

W. Röllig (1970), Das Bier im Alten Mesopotamien. Berlín.

M. Rosa Oliver (2006), «Indagación sobre la construcción de espacios femeninos en los intersticios del mandato masculino en la Mesopotamia paleobabilónica». Córdoba, Argentina.

J. Sanmartín (1999), Códigos legales de tradición babilónica. Barcelona.

J. Sanmartín (2005), Epopeya de Gilgameš, rey de Uruk. Barcelona.

C. Saporetti (1984) 40-48, Le leggi della Mesopotamia (Studi e manuali di archeologia, 2), Firenze.

R. Yaron (1988)². The Laws of Ešnunna. Leiden. 
8.2. Inscripción cuneiforme de los textos

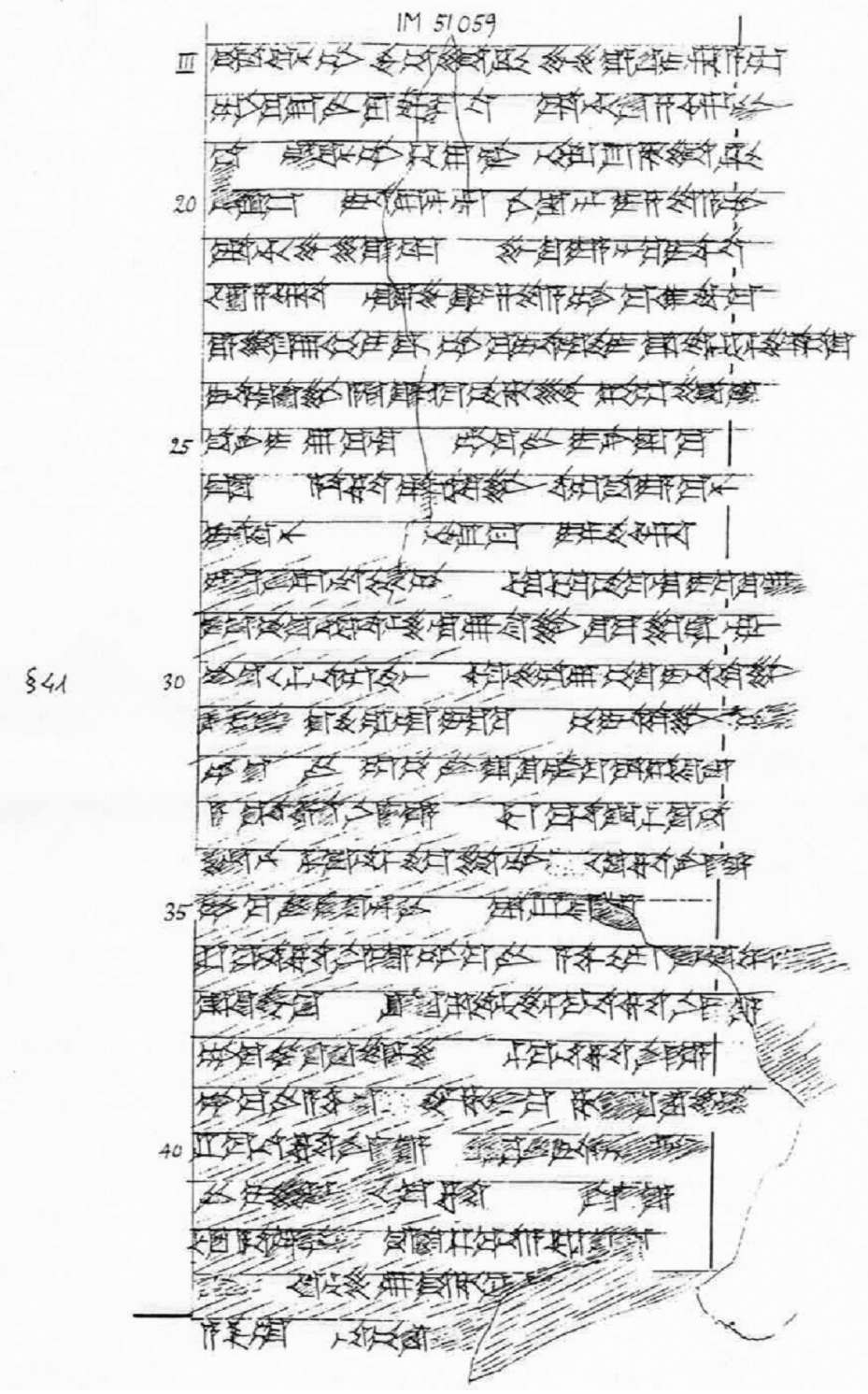


$\{1081$

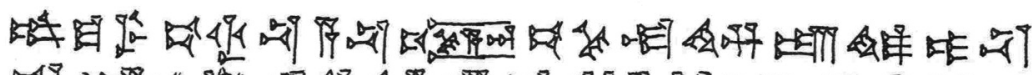

䌾

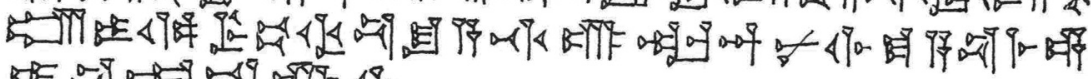
B

§109)

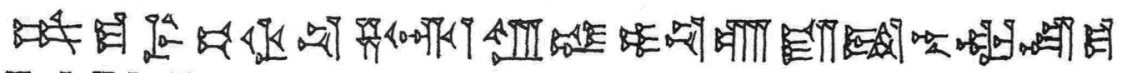
留 4700949 䣄

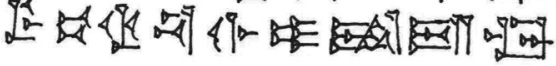

§110)

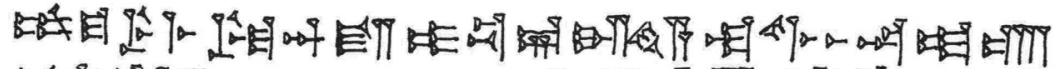

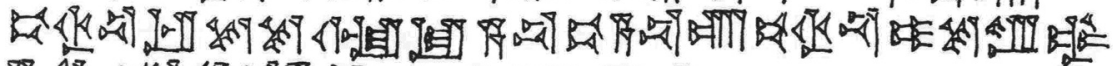
居 ब和

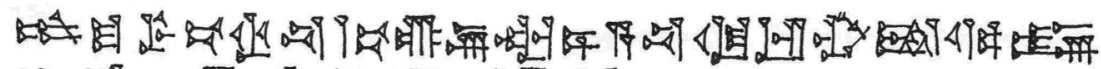
सि को व 


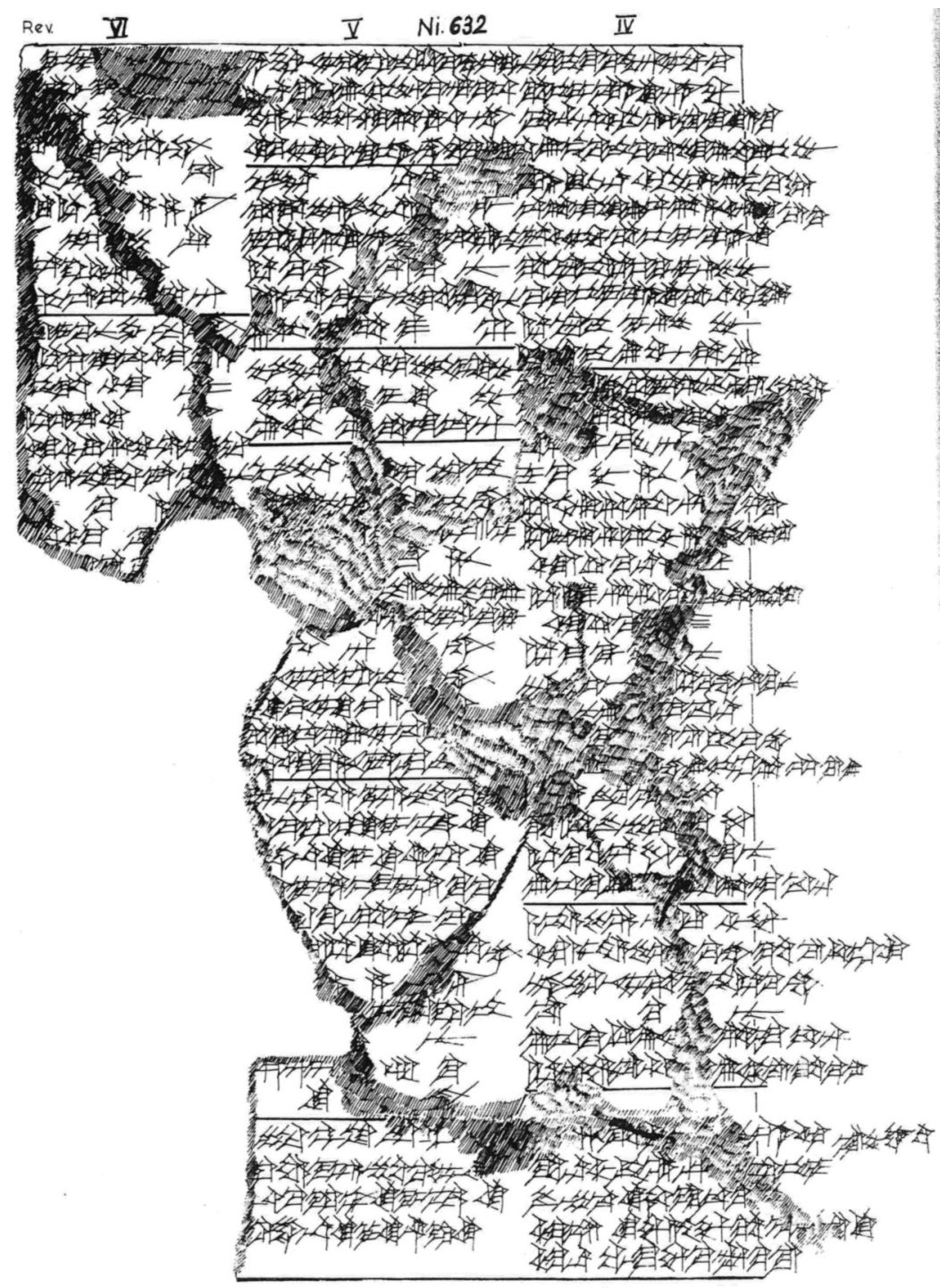




\section{Altassyrische Gesetze.}

(VAT 10000)

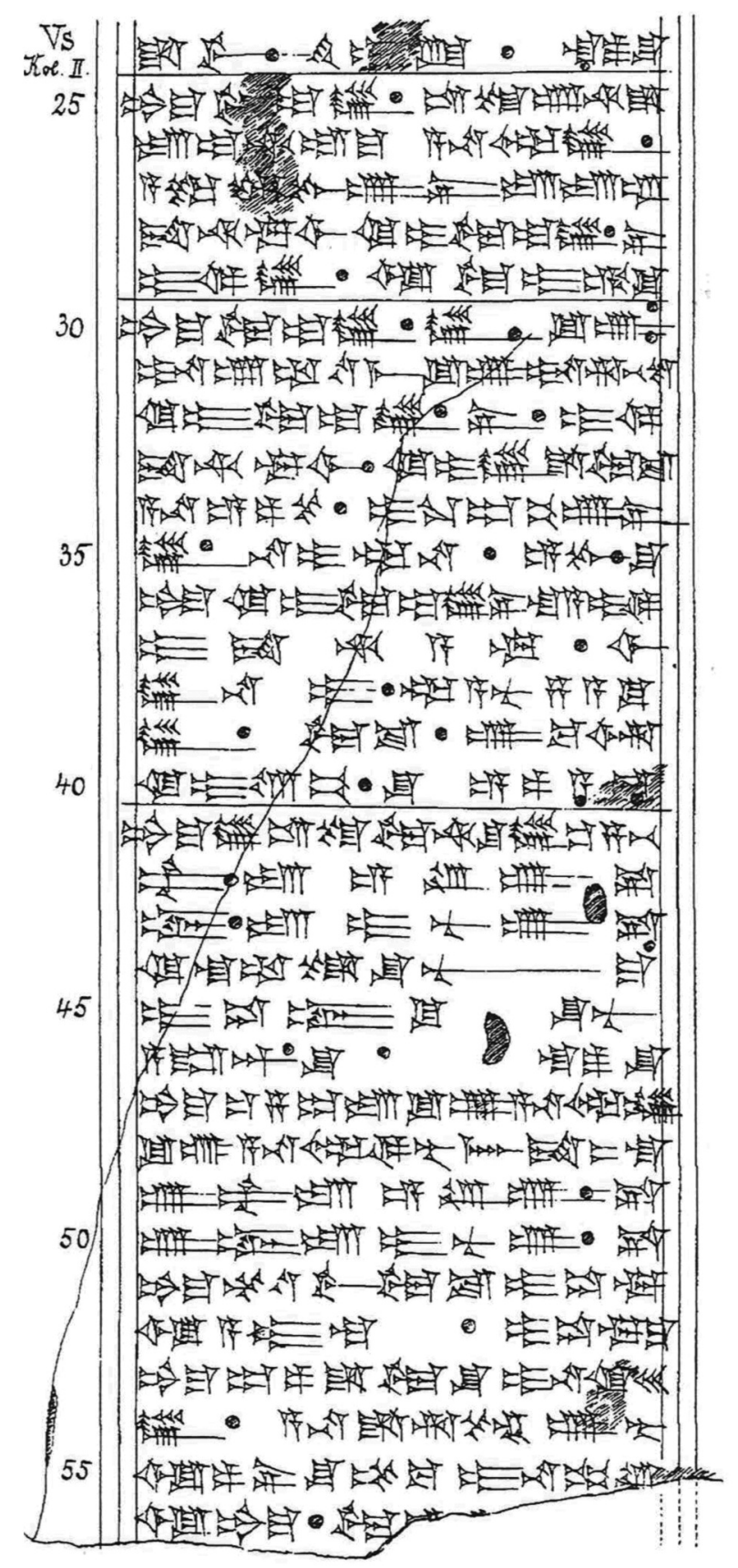

